\title{
An Automation System Design for Dough Kneaders and Dosing Machines with Microprocessor Based and 5 Flows ${ }^{\#}$
}

\author{
Hasbi Apaydın ${ }^{1}$, Şükrü Kitiş* ${ }^{2}$
}

Accepted $15^{\text {th }}$ August 2014

\begin{abstract}
In this study, an automation system is designed for bakeries, biscuit factories, flour and bakery products used dough kneading and dosing machines. This microprocessor-based design, made of 5-flowing flour and water dispensing operation. For this, the area is very easy to become available and can be programmed PIC16F877A microcontroller used. This automation system isn't used in most of the plants and mixing ratios. Therefore the operator's ability and speed very important for mixing ratios and the production rate without automation system. This is quite a challenge, raw material and leads to a loss of time. This study, carried out the difficulties that emerged from the automation system can be provided at low cost and hassle-free.
\end{abstract}

Keywords: Dough-mixing, metering, automation, microprocessor-based automatic control

\section{Introduction}

Dough emerges as a quite significant product at flour and bakery manufacturing plants and factories. There are various stages during dough making. Primarily, it is required storing dough in moisture free enviroments then transporting to dough kneaders at intended amounts and mixing with proper rates of water in order to become a dough. Even if this process seems to be easy, it is very exhausting. With the implementation of this study, it is mixing problem of not being the intended rates, difficulty in this process and leeway will be solved. Therefore, existing lines which have not single or double flow automation systems have investigated and developed a method as a solution to that case. For this method, a five flow system is considered. In this system, 24 V, D.C., pneumatic walves (K1-K2-K3-K4-K5) enable the flow of flour from silo to kneaders. $24 \mathrm{~V}$, D.C., selenoid walves (S1-S2-S3-S4-S5) allow water flow to the same kneaders. Motors (M1-M2-M3-M4-M5) provide to take flour from silo and flour line. Silo motor, (M6), prevents that the line remains without flour by means of SW1 switch. Furthermore, in order to be able to calculate the liter of water which is sent to the kneaders, it is required fixing of cold water meters (supals1-supals2-supals-3, supals-4, supals-5) after each selenoid walve. Motors, selenoid walves, pneumatic walves, cold water meter are controlled with the designed system. Additionally, various modes which operator is able to make a choice take place and the operator is able to decide on whether which kneader turns on or off and intended rates.

\section{Flow Line}

Flow line is shown as in figure 1 [1]. Firstly, flour which comes with hopsacks is dumped to flour tank.

This dumped flour is transported to the silo through the spiral and

\footnotetext{
12 Dumlupınar Üniversitesi Simav-Kütahya

* Corresponding Author: Email: sukru.kitis@dpu.edu.tr

\# This paper has been presented at the International Conference on Advanced Technology\&Sciences (ICAT'14) held in Antalya (Turkey), August 12-15, 2014.
}

stored here by protecting moisture.Flour stored in the silo supplies the flour line via motor, M6. Fullness of the line is monitored by the switch of SW1. When the SW1 is active, M6 is enabled to stop. According to the modes which are selected by the operator from the program menu one of the walves, K1 or K5, is opened and therefore, ones related to motors, M1 - M5, and switches, S1 - S5, are made dosing process by actuating at given time instants. In the designed system, the silo is of $1000 \mathrm{~kg}$ capacity, kneaders are $100 \mathrm{~kg}$ capacity. These selections might have variable formations with respect to the demands of the factory.

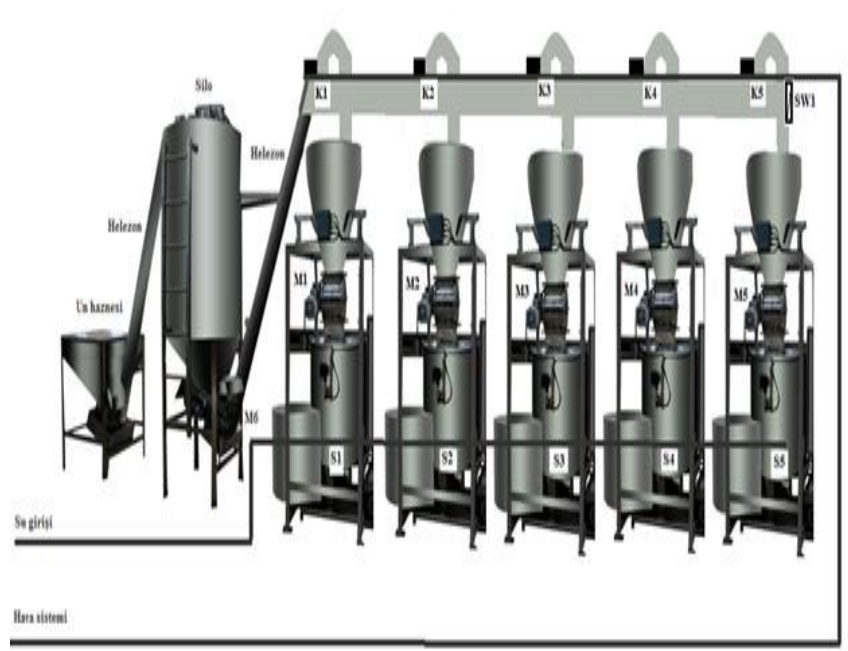

Figure 1. Flow line for automation system

\section{Control Circuit Schematic}

Control circuit schematic is shown at figure 2. This circuit has designed around the frame of PIC16F877A. Inside the circuit, data comes from the cold water meter with pulse-out is evaluated as well. With this meter, the liter of water that is added into the kneader is calculated so that flour and water mixture can adjust proper amounts. It has seen that with opening the pneumatic 
walves $100 \mathrm{~kg}$. Flour has transported into system within 94 seconds. The amount of water required to added into the this flour mixture is adjusted according to the direction of intendion operator with water meter.

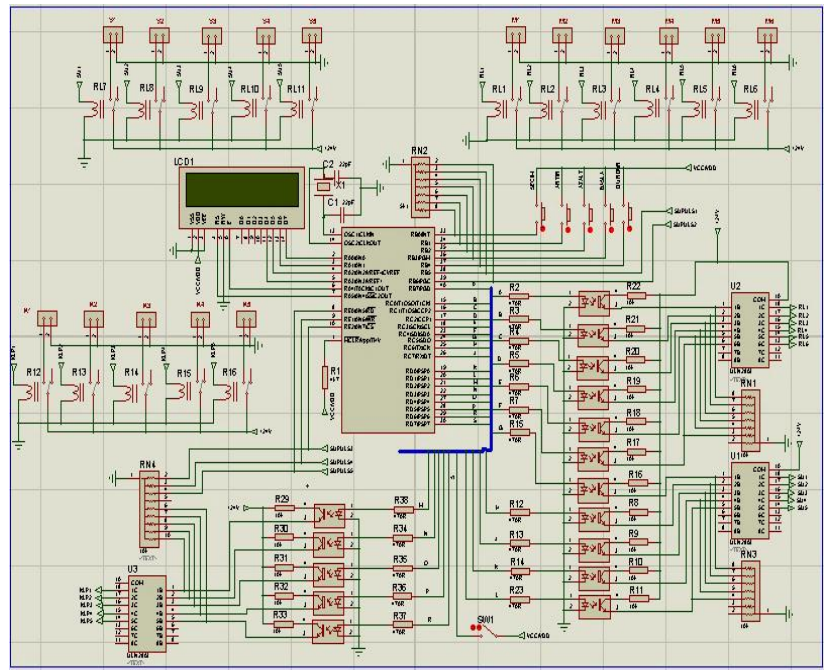

Figure 2. Mainboard for automation system

\section{Power Supply}

In the automation system, power supply segment designed for 5 V D.C. which is necessary to work PIC and 24 V D.C. which is necessary to work selenoid walves, pneumatic walves, contactors with the aim of used to work motors as in figure 3 . In the designed application [2-4], it is prefered $2 \times 24$ V A.C. transformer with independent secondary tapes that is why PIC is resetted and affected from noise received from system. After 24 V A.C. going out from independent secondary tapes are rectified, it is reduced to $12 \mathrm{~V}$ by using 7812 and then 7805 for $5 \mathrm{~V}$ it is provided to supply power for control circuit board.

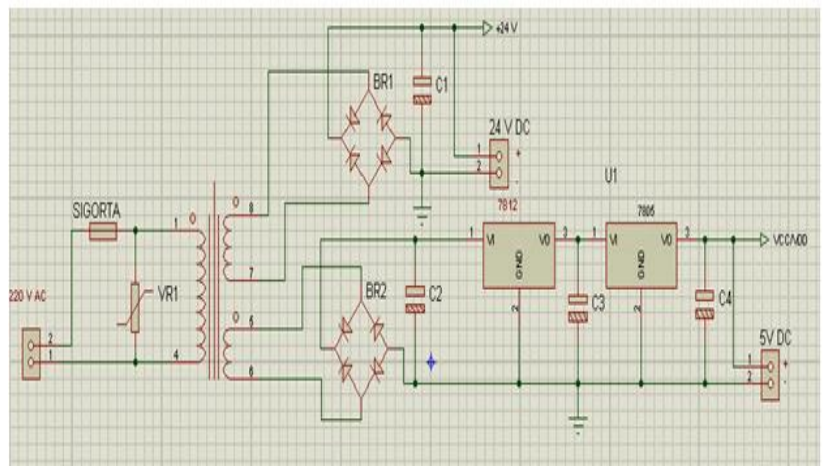

Figure 3. Power supply for automation system

\section{Program}

By means of LCD display which is on the control circuit board operator makes selections and controls. LCD display image is shown as figure 4 and figure 5 . There is a program with menu which operator is able to make a selection as Mod1, Mod2, Mod3, Mod4, Mod5, Mod6 and within these menus how many kilos of flour and liters of water need to be used for one of each flow line. In these programming flour and water amount can be increased and decreased one by one. Mod6 is a mixed mode and it activates inputs of flour and water to the kneaders by opening all 5 line simultaneously. The flow chart for automation system is shown figure 6.

\begin{tabular}{|c|c|}
\hline $\begin{array}{l}U_{n}=50 \mathrm{~kg} \bmod 1 \\
5 \mathrm{u}=501 \mathrm{t}\end{array}$ & $\begin{array}{l}15 u=501 \mathrm{lt} \quad \bmod 1 \\
U_{n}=50 \mathrm{~kg}\end{array}$ \\
\hline 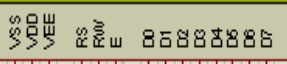 & 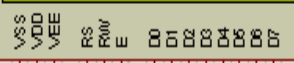 \\
\hline
\end{tabular}

Figure 4. Mod1 LCD screen

\begin{tabular}{|c|c|}
\hline $\begin{array}{l}U_{n}=50 \mathrm{~kg} \quad \bmod 2 \\
S_{u}=50 \mathrm{lt}\end{array}$ & $\begin{array}{l}15 \mathrm{u}=50 \quad 1 \mathrm{t} \quad \bmod 2 \\
U_{n}=50 \mathrm{~kg}\end{array}$ \\
\hline 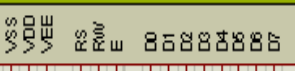 & 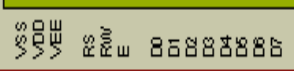 \\
\hline
\end{tabular}

Figure 5. Mod2 LCD screen

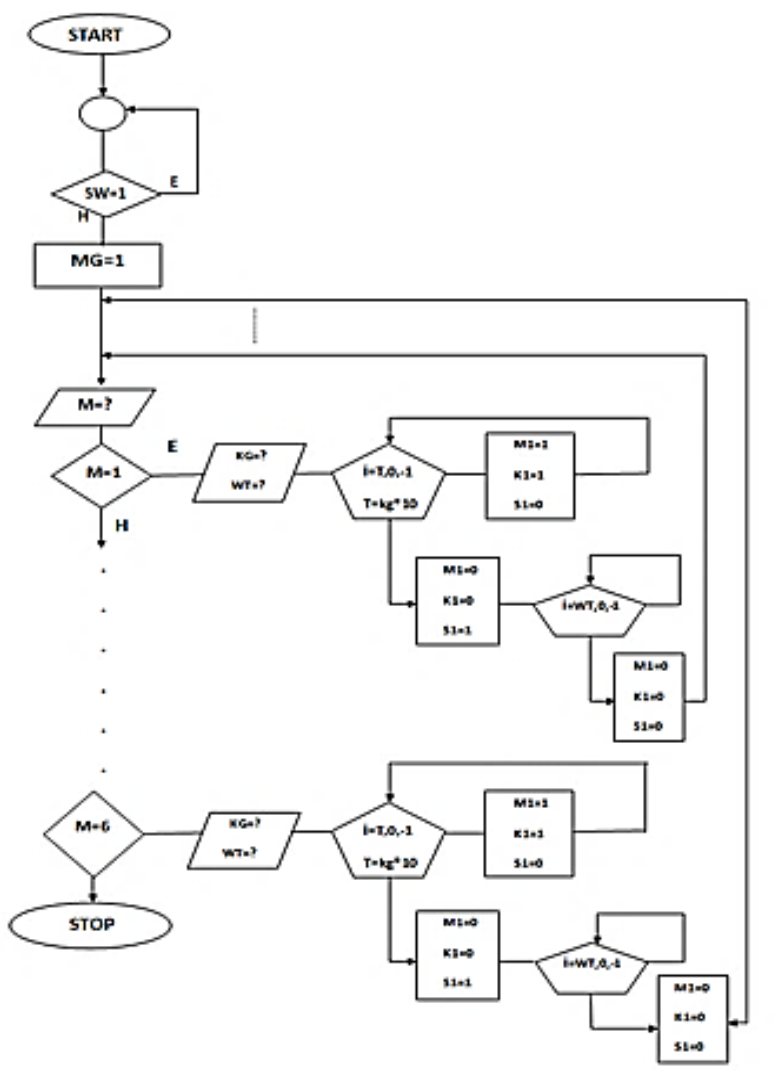

Figure 6. The flow chart of software for automation system

\section{Conclusion}

Commercially available and specially dough kneading machine are often used at bread production firms, specifications are as follows;

- $100 \mathrm{KG}$. FLOWER

- $2.2 \mathrm{KW} \mathrm{380/400} \mathrm{VOLT}$

- $160 * 90 * 115 \mathrm{CM}$.

- Q $90 \mathrm{CM}$.

- $300 \mathrm{KG}$

In this application, 5 pieces are designed from this kneading machine. Calculation of the amounts of classical bread components has a simple formulation for $100 \mathrm{~kg}$ flour. Classical bread formulation, is stated as \% follows;

$55-60 \%$ water (variable according to water lifting capacity of flour)

3-4 \% fresh yeast (variable according to season and ambient temperature)

0,5-1\% bread ingredients (variable the rate of usage)

$1.5-1,75 \%$ salt (variable according to dry matter amounts and 
fresh dough) [6-9]

With this model, bread and water amounts will be measured by operator demands; if 5 flow systems where kneading system is empty and broken, the flow will be supplied through the broken and empty system. This procedure of mixture and time are supplied as follows;

Mixing of flour, water and bread ingredients (20 min.)

Kneading (30-35 min. with mixer)

Adding salt (5 min.)

Adding yeast ( $5 \mathrm{~min}$.)

Mass fermentation- conditioning (20 min.)

Cutting, weighing, and forming (10 min.)

Part fermentation (75. min)

Cooking

Cooling

Packing [6-9]

Graphic 1: Mod1-Mod5 times

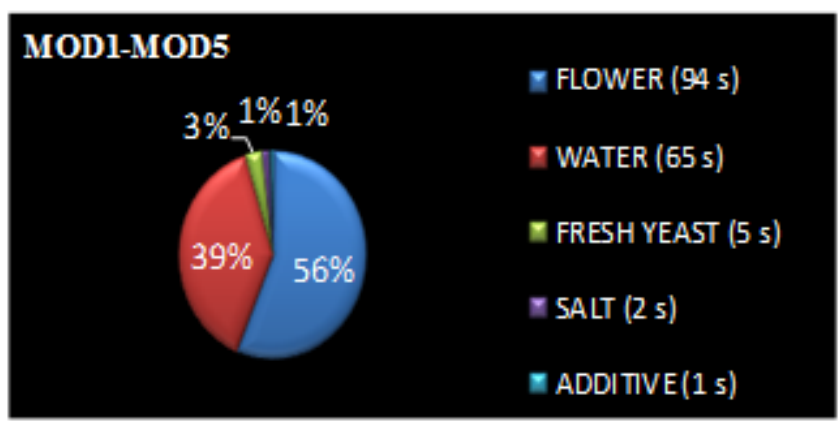

Graphic 2: Mod6 time

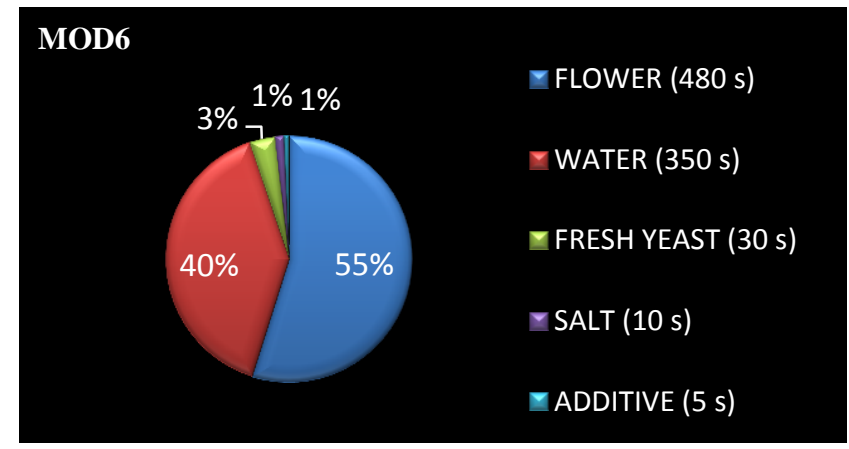

Graphic 3:Time without automation

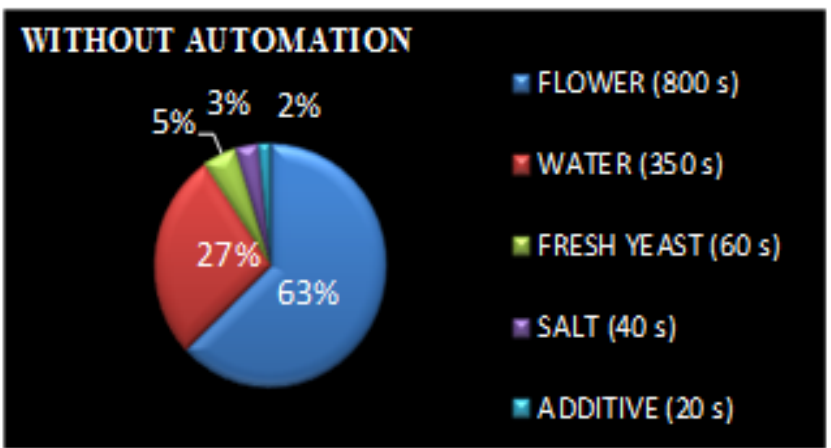

In this study; if in the flow line, only one kneading machine will work [10], the elapsed time is shown as graphic 1 . When 5 line is active; in other words 5 kneading machine work [10], the elased time is shown in graphic 2 . In this system, the most important mixture matter is flour. Without automation system, under operator control, giving the flour to the system, it is observed that, time can be $800 \mathrm{~s}$ according to the initiative of the operator. Mostly time is saved in automation systems. These automation system designed by PIC microcontrollers with picbasic [11-12] and these systems algorithm shown figure 6. Expansion time of filling flour, delay time of adding of the other ingredients to the mixture, and mixture will not be easy. As this reason, the contribiton of the automation system, these periods will be shorten and the mixture will ocur at a minimum time. Difference of our system from other systems; system has difference programs and this programs can change with algorithm. Algorithm has a flexible program. Mainboard for automation system is designed by PIC and PIC basic codes. Advantages of our system from other systems; system has mainboard with LCD screen, power supply with 5V D.C. and small, useful, visual. In this system labor and mistakes close to zero. In the next study, not only flour and water mixture but also all steps will be controlled by the automation system.

\section{References}

[1] http://www.tr.all.biz/un-hamur-otomasyonu-g93245

[2] Erol Y., PIC Kontrollü Röle Sürücü, Ocak 2008, Bilim ve Teknik Dergisi (TÜBİTAK), syf:84-85

[3] Y1lmaz H., Sarıtaş M., Ekmek üretiminde programlanabilir mantıksal kontrol cihazının kullanılması. Gazi Üniv. Fen Bil. Enst. Y.Lisans Tezi, Ankara,2005

[4] Yılmaz H., Sarıtaş M., Ekmek üretim hattında PLC cihazının kullanılması http://www.emo.org.tr/ekler/f6242793017047d_ek.pdf

[5] http://www.endustriyelmutfakfiyat.com/index.php?cPath=6 8

[6] www.vankim.com/Files/Ekmek\%20uretim\%20teknolojisi(1 ).pdf Yrd. Doç. Dr. Murat Yılmaztekin

[7] Doğan İ.S., Yıldız Ö., Ekmek makinelerinde kullanılan farklı bileşen seviyelerinin ekmek kalitesi üzerine etkisi. G1da(2009) 34 (5):295-301

[8] Gujral H.S., Singh N., Effect of additives on dough development, gaseous release and bread making properties. 1999. Food Res Int 32 (10) : 691-697.

[9] Doğan İ. S., Yıldız Ö., Taşan B., Determination of the bread-making quality of flours using an automatic bread machine. Turk J Agric For 36 (2012) 608-618@ TÜBİTAK doi:10.3906/tar-1202-48.

[10] Yanhui S., Meng G., Ningning L., Jianhong D. An Intelligent Management System on Load Characteristic Identification and Power Supply Safety on Campus. 2011 Third International Conference on Measuring Technology and Mechatronics Automation

[11] Altınbaşak O. (2005), Mikrodenetleyiciler ve PIC programlama. Altaş Yayınevi

[12] Hellebuyck C. (2003), Programming PIC microcontrollers with Picbasic. Newnes Publications. 